\title{
Local site amplification and damage to wooden houses in Shimoenoki, Tottori, Japan, by the 2000 Western Tottori Earthquake
}

\author{
Koji Matsunami ${ }^{1}$, Takeshi Morii ${ }^{2}$, Yuka Okamoto ${ }^{2}$, and Teizo Fujiwara ${ }^{2}$ \\ ${ }^{1}$ Disaster Prevention Research Institute, Kyoto University, Kyoto 611-0011, Japan \\ ${ }^{2}$ School of Environmental Science, University of Shiga Prefecture, Hikone 522-8533, Japan
}

(Received January 17, 2002; Revised July 26, 2002; Accepted July 29, 2002)

\begin{abstract}
The degree of damage to wooden houses in the vicinity of the source area of the 2000 Western Tottori Earthquake was very low compared to the 1995 Hyogo-ken Nanbu Earthquake. Shimoenoki in Hino Town, however, suffered remarkable damage compared to other villages, particularly to residential wooden houses. Furthermore, although Shimoenoki is a small area of only $300 \times 400 \mathrm{~m}^{2}$, the damage varied markedly from the foot of the mountains through central Shimoenoki to the Hino River. From the damage distribution based on a survey of all wooden houses, the local site-amplification characteristics estimated from aftershock records, and the transfer functions of wooden houses evaluated using microtremors, the spatial variation of damage appears to be attributed to the variation in site-amplification factors at frequencies between 2 and $5 \mathrm{~Hz}$, which is close to the first natural frequency of wooden houses.
\end{abstract}

\section{Introduction}

The 2000 Western Tottori Earthquake, a magnitude 7.3 $\left(\mathrm{M}_{\mathrm{j}}\right)$ event recorded by the Japan Meteorological Agency (JMA), occurred near Hino Town in the western part of Tottori Prefecture, Southwestern Honshu, Japan, at 13:30 on October 6, 2000. Seismic intensities exceeding 6 on the JMA scale were observed at Higashimoto in Sakaiminato City and at Neu in Hino Town. Although the magnitude of the earthquake is similar to that of the 1995 Hyogo-ken Nanbu Earthquake (i.e., the Kobe Earthquake), the damage incurred in the source area as a result of the 2000 Western Tottori Earthquake (i.e., the Tottori Earthquake) was much lower, as clearly presented in the report by Hayashi et al. (2001). In that report, from the distribution of toppled tombstones, the peak ground velocity in the source area during this earthquake was determined to have been greater than $80 \mathrm{~cm} / \mathrm{s}$, which is comparable to that inferred for the most heavily damaged areas in the Kobe Earthquake. In addition, from a comparison of the damage to wooden houses in areas experiencing similar peak ground velocities during both earthquakes, no significant difference was found between the ratio of minor damage to dwelling in the two earthquakes. However, the ratio of severe damage to housing in the source area for the Tottori earthquake was much lower than for the Kobe Earthquake. The most obvious evidence of the overall lower severity of damage in the Tottori earthquake is the fact that no fires were triggered by the earthquake and no lives were lost. The low severity of damage in this area has been attributed generally to the hard soils and mountain geology in the source area, the low population density compared to Kobe City, and the timing of the earthquake, which struck

Copy right(c) The Society of Geomagnetism and Earth, Planetary and Space Science (SGEPSS); The Seismological Society of Japan; The Volcanological Society of Japan; The Geodetic Society of Japan; The Japanese Society for Planetary Sciences. after lunch on a fine autumn weekday, resulting in no triggered fire.

However, the damage incurred in towns in the vicinity of the source area, including Shimoenoki, Kurosaka, Shimokurosaka, and Yasuhara in Hino Town, was severe (Kitahara et al., 2001; Kobayashi et al., 2001). Shimoenoki, which is about $10 \mathrm{~km}$ southeast of the epicenter of the main shock, suffered remarkably severe damage, particularly to residential wooden houses. Of the total of 149 wooden buildings, mostly typical Japanese two-story structures with ceramic tile roofs, damage certificates were issued for 26 collapsed buildings and 96 partially collapsed buildings (Tottori Prefectural Office). The remaining 27 houses also suffered some damage. Furthermore, although Shimoenoki is a small area of only $300 \times 400 \mathrm{~m}^{2}$, the damage to wooden houses varies spatially from the foot of the mountains through central Shimoenoki to the Hino River, which is the largest river in Hino Town (Matsunami et al., 2001).

In this study, the cause of such spatial variation of damage in Shimoenoki is examined based on the damage distribution obtained by a post-earthquake survey of all wooden houses, local site-amplification characteristics estimated using aftershock records, and the vibration characteristics of wooden houses evaluated from microtremor measurements. The examination assumes linear behavior for soils and wooden houses in response to weak motions due to aftershocks and microtremors.

\section{Main Shock and Overview of Geology and To- pography}

Figure 1 is a location map of the main shock and analyzed aftershocks, showing the target areas of Shimoenoki and Unoike in Hino Town. The magnitudes and hypocenters of these events were determined by the Earthquake Prediction Re- 


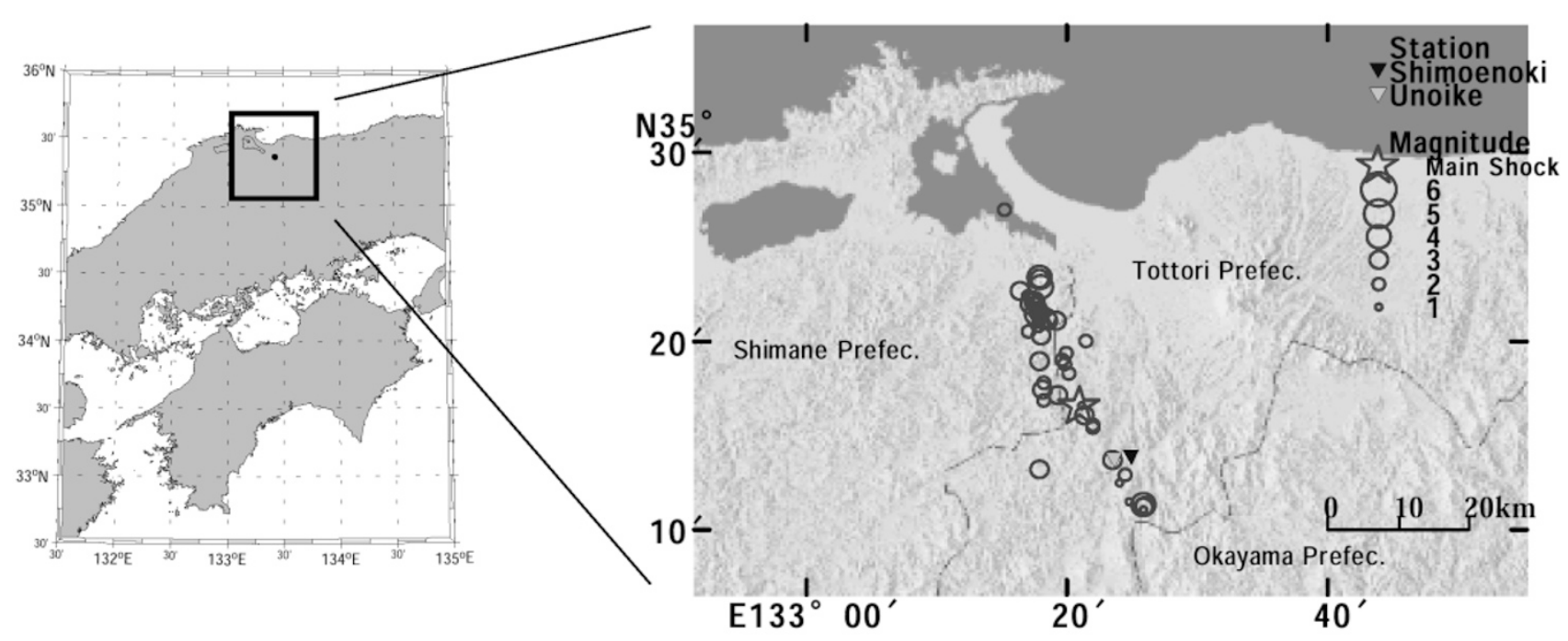

Fig. 1. Epicenter distribution of the main shock and analyzed aftershocks, and location of seismic observation points. Observation points in Shimoenoki and Unoike are denoted by closed and open triangles. Includes 5 temporary stations in Shimoenoki and the TTRH02 station of Kik-Net in Unoike.
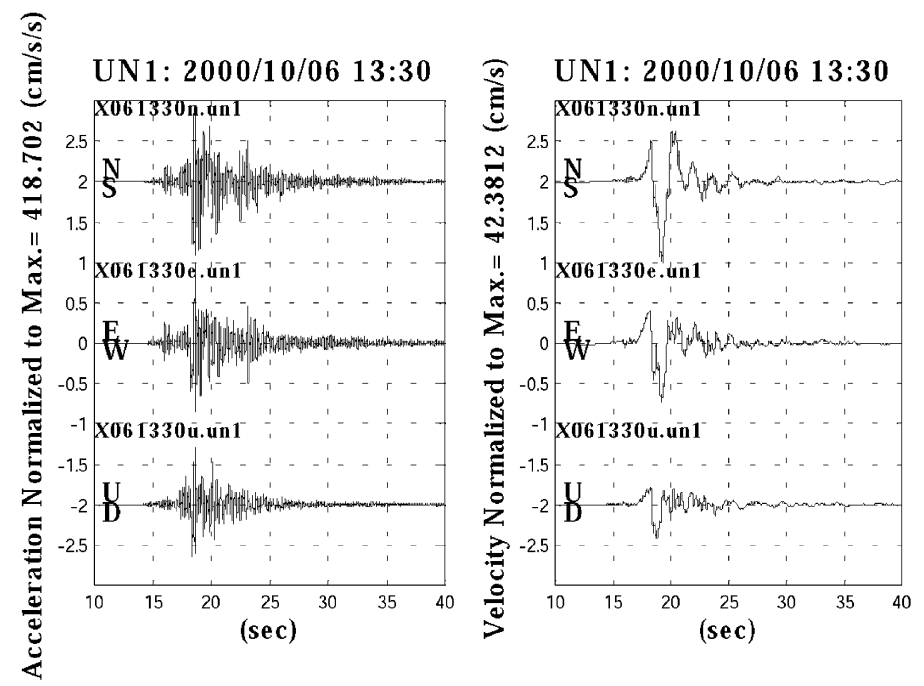

Fig. 2. Waveforms of the main shock observed at the borehole site (GL $-100 \mathrm{~m}$ ) of the KiK-Net station TTRH02, denoted UN1. (Left) Acceleration, (Right) Velocity.

search Center (EPRC) of Kyoto University. According to the Fundamental Research on Earthquakes and Earth's Interior Anomalies (FREESIA) project of the National Research Institute for Earth Science and Disaster Prevention (NIED), Japan, the source mechanism of this earthquake was a leftlateral strike-slip (Strike $150^{\circ}$, Dip $85^{\circ}$, Rake $-9^{\circ}$ ) fault movement. The fault associated with the earthquake did not appear clearly on the surface. As can be seen from Fig. 1, the aftershock area extends north and south from the epicenter of the main shock. A KiK-Net (the Kiban Kansoku Network for strong ground motions operated by the NIED) station is located at Unoike, and consists of two sets of three-component accelerometers. One set is installed on the surface (UN2), while the other is situated $100 \mathrm{~m}$ below the surface in a borehole (UN1). Unoike, in the vicinity of the source area, experienced strong ground motions during the main shock. Fig- ure 2 shows waveforms of the main shock observed at the borehole site, UN1. Larger ground motions were observed in the N-S component of the records, with a peak acceleration of about $418 \mathrm{~cm} / \mathrm{s}^{2}$ and peak velocity of about $42 \mathrm{~cm} / \mathrm{s}$. Shimoenoki, located about $2 \mathrm{~km}$ east of Unoike, is also expected to have experienced strong ground motions during the main shock.

Figure 3 is a topographical map of Hino Town. Steep granitic mountains with an altitude of 700 to $1100 \mathrm{~m}$ above see level rise around Hino Town (Tottori Prefecture Office, 1993). The Hino River meanders through the mountain to eventually flow through Hino Town. Several villages are located adjacent to the Hino River and its tributaries, and at the foot of the mountains. Shimoenoki is located along the Hino River, and the central part of Shimoenoki is built on a gently sloping plain composed of river terraces, extending from the 


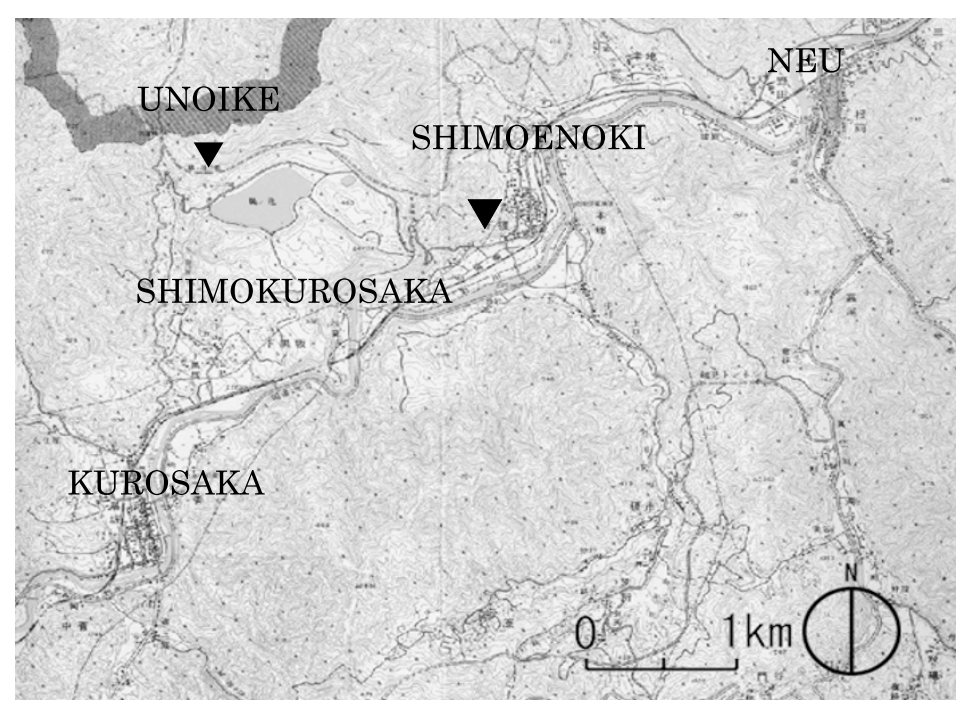

Fig. 3. Topographical overview of Hino Town. The Hino River flows through Kurosaka, Shimokurosaka, Shimoenoki and Neu through steep granitic mountains. Most villages are located along the Hino River and its tributaries. Shimoenoki and Unoike are denoted by closed triangles, and are horizontally separated by about $2 \mathrm{~km}$.

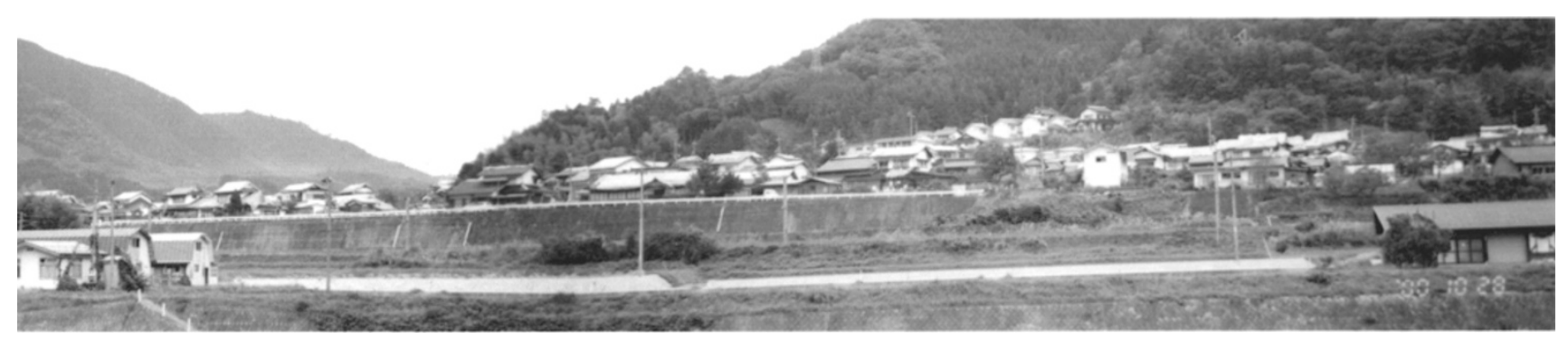

Photo 1. Overview of Shimoenoki in Hino Town.
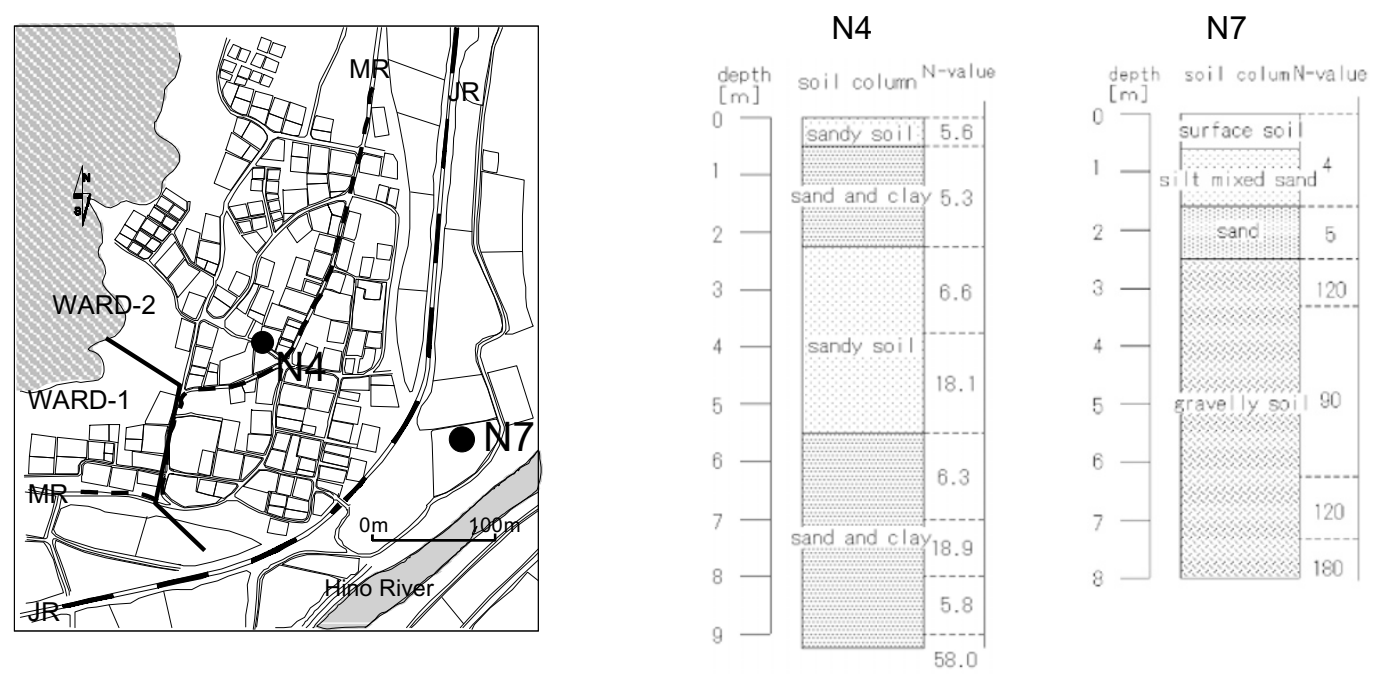

Fig. 4. (Left) Overview of Shimoenoki and location of the two boring sites N4 and N7. Shimoenoki is located on a plain that slopes gently from the foot of the mountains in the northwest to the Hino River in the southeast and consists of two wards (WARD-1 and WARD-2). WARD-1 is located in the southwest of Shimoenoki and is much smaller than WARD-2. The dashed line (MR) shows the main road, and JR denotes the Japan Railway. N4 is located in central Shimoenoki, and N7 is located close to the Hino River. (Right) Soil columns and N values for sites in Shimoenoki. N value of N7 increases abruptly to 120 at a depth of $2.5 \mathrm{~m}$, whereas that of N4 remains at 5 to 18 to a depth of $9.5 \mathrm{~m}$. 
Table 1. Criteria for judgment of damage level (DL) of wooden houses.

\begin{tabular}{ccccccc}
\hline $\begin{array}{c}\text { Damage level } \\
(\mathrm{DL})\end{array}$ & Roof tile & Outer wall & Foundation & Column & $\begin{array}{c}\text { Tilt of column } \\
\text { (in rad.) }\end{array}$ & Interior of rooms \\
\hline 0 & & & & No damage & \\
1 & Shift & Micro-crack & & & $1 / 500$ & $\begin{array}{c}\text { Shoji } \\
2\end{array}$ \\
3 & Falling off & Major-crack & Micro-crack & Shift & & Glass and sliding paper-door \\
4 & & Exfoliation & Major-crack & & $1 / 100$ & Exfoliation of inner wall \\
5 & & & & & $1 / 30$ & \\
6 & & & & Collapse & & \\
\hline
\end{tabular}

foot of the mountains to the river. The distance between the foot of the mountains and the river is about $300 \mathrm{~m}$, with a maximum difference of around $40 \mathrm{~m}$ in elevation. Photo 1 and the map of Fig. 4 give a topographical overview of Shimoenoki.

The available information on the subsurface structure of Shimoenoki is limited. Boring data down to a depth of about $10 \mathrm{~m}$ has been obtained at two sites (N4 and N7, Fig. 4) in Shimoenoki, and rough information on the depth to the granitic layer below site N4 has been collected. The boring data and depth to the granitic layer at site N4 were provided by a water services construction company in Hino Town, and information for site N7 was provided by the Hino Town Office. Site N4 is located in central Shimoenoki where the earthquake damage was relatively severe. Site N7 is located close to the Hino River. Figure 4 also shows the soil depth profile and $\mathrm{N}$ values obtained by the standard penetration test (SPT) at both sites. The SPT N-value is the blow count necessary to penetrate $30 \mathrm{~cm}$ into the layer using a 63.5 $\mathrm{kg}$ hammer falling freely from a height of $75 \mathrm{~cm}$ (Yoshida, 1993). As shown in the figure, the $\mathrm{N}$ value for site $\mathrm{N} 4$ ranges from 5 to 18 at depths shallower than $9 \mathrm{~m}$, and becomes 58 at a depth of about $9.5 \mathrm{~m}$. For site N7, the N value is 4 to 5 at depths shallower than $2.5 \mathrm{~m}$ and suddenly increases to 120 at a depth of $2.5 \mathrm{~m}$. From this data it is obvious that the soils near the Hino River are much harder than in central Shimoenoki. Rough information on the depth to the granitic layer suggests a depth of 20 to $30 \mathrm{~m}$ below site N4.

For the subsurface structure of Unoike, the velocity logging data provided by NIED can be used as a reference. The soil is composed of gravel from the surface to a depth of $10 \mathrm{~m}$, overlying a granitic layer. The S-wave velocity is greater than $500 \mathrm{~m} / \mathrm{s}$ at depths of more than $20 \mathrm{~m}$, reaching $790 \mathrm{~m} / \mathrm{s}$ at a depth of $100 \mathrm{~m}$ at borehole station UN1.

\section{Damage Distribution for Wooden Houses}

Shimoenoki is divided into two wards as shown in the map in Fig. 4. One ward encompasses the southwest part of Shimoenoki, called WARD-1, and is an old village in which most buildings are wooden houses of 100 to 120 years in age. The other ward, WARD-2, consists of relatively new buildings built in the periods 1974 to 1976 and 1979 to 1985 when the roads in WARD-2 were repaired. The authors conducted a survey of damage to all buildings in WARD-1 and WARD2 after the earthquake, a total of 139 buildings including 122 wooden houses. All the wooden houses are residential twostory houses with ceramic tile roofs and similar floor plans. Thus, houses with similar structure are distributed in Shimoenoki, allowing the local soil conditions to be discussed based on the damage distribution for wooden houses.

According to the damage survey of Shimoenoki, no dwellings collapsed completely, while 16 suffered partial collapse and the remaining suffered minor damage. Rooftile damage was remarkably high in Shimoenoki compared to other villages, with more than $80 \%$ of wooden houses sustaining damage to roof tiles (dislodged or shifted tiles). As can be seen in Photo 1 , most of the roofs are covered with plastic sheets as a temporary fix for tile damage.

The items evaluated in the damage survey were the type of building (i.e., house, factory or storehouse), year of construction, number of floors, plan of building, damage to individual parts of building (e.g., roof, wall, frame or foundations) and tilt of columns. As very few buildings collapsed or became tilted by more than $1 / 30 \mathrm{rad}$, the damage to buildings was classified into 7 levels based on the degree of damage to individual parts of buildings. Although several instances of ground failure were identified, these instances were not included in the judgment of damage level because the present study focuses on the damage due to shaking. Table 1 lists the criteria for judging the damage level (DL). The DL of each house was determined by referring to these criteria.

A distribution map of the DL is shown in Fig. 5. The DL can be seen to vary from the foot of the mountains in the northwest to the Hino River in the southeast. The DL is 0 to 1 near the foot of the mountains in the northwest, whereas the southwestern area (WARD-1) and the area between the foot of the mountains and the main road (MR) contain many houses with a higher DL of 3 to 5 . In the area between the Hakubi-Line of Japan Railways (JR) and the main road, severely, moderately, or slightly damaged houses coexist, but many houses have a moderate DL of 1 to 3 . Thus, this area of Shimoenoki appears to have suffered moderate damage. In this way, Shimoenoki can be roughly divided into three zones based on the DL; a slight-damage zone (DL of 0 to 1) near the foot of the mountains, a moderate-damage zone (DL of 1 to 3 ) between the JR Hakubi-Line and the main road, and a severe-damage zone (DL of 3 to 5) between the foot of the mountains and the main road, and in WARD-1. These three zones are shown in Fig. 5 along with a plot of the proportion of each DL in each zone. From this figure, the proportion of 

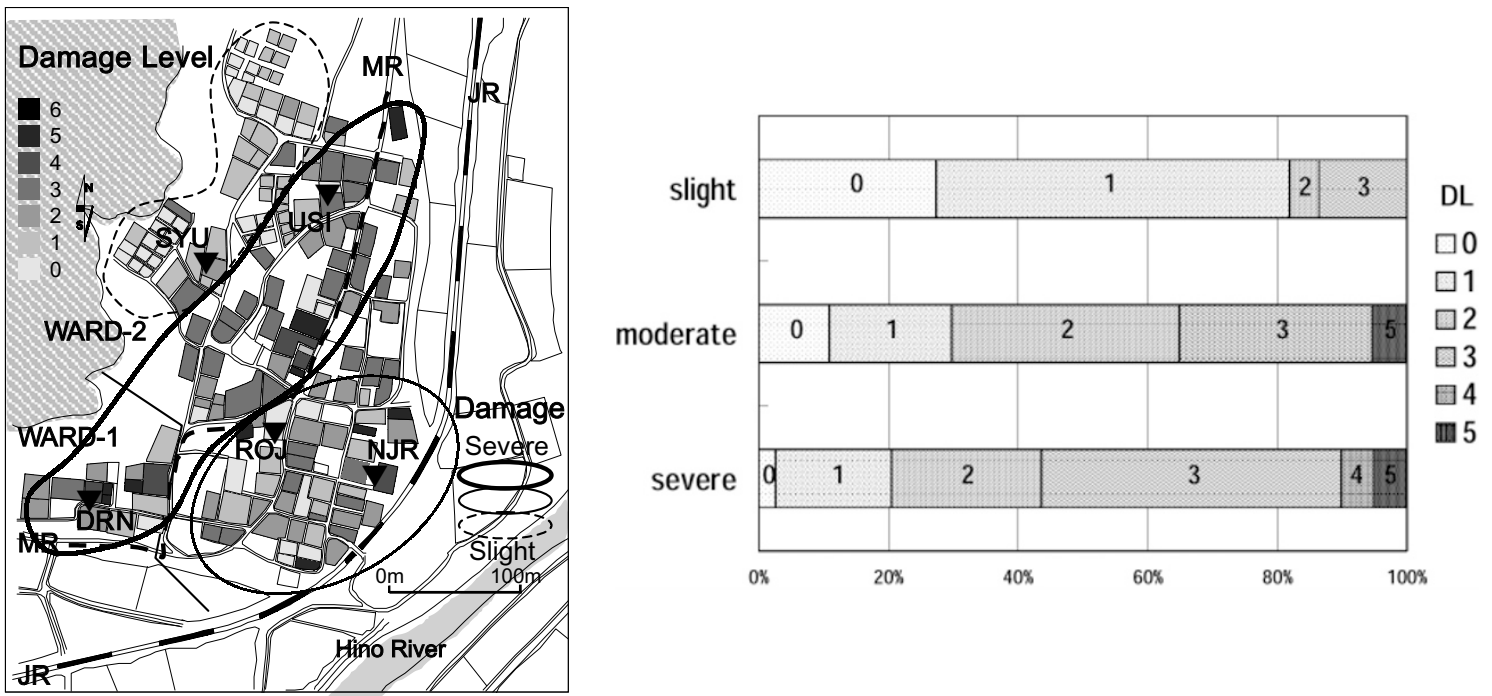

Fig. 5. (Left) Damage distribution for wooden houses. The dashed line outlines the slight-damage zone, the thick line indicates the boundary of the severe-damage zone, and the thin line marks the moderate-damage zone. (Right) Comparison of proportion of each damage level (DL) in the three damage zones. The proportion of $\mathrm{DL}>3$ increases from 15 to $55 \%$ from the slight-damage zone to the severe-damage zone.
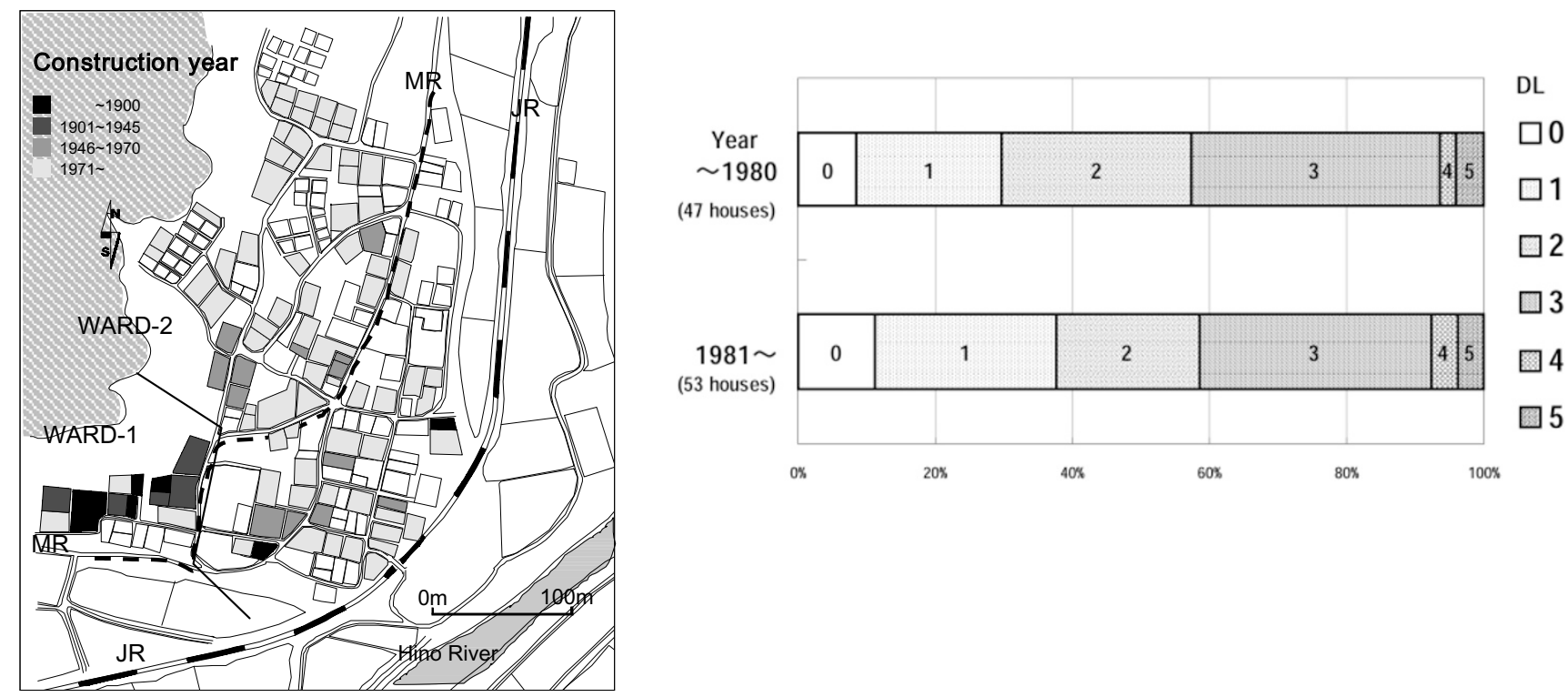

Fig. 6. (Left) Distribution of year of construction for wooden houses in Shimoenoki. Year of construction for wooden houses was classified into four periods: prior to $1900 ; 1901$ to $1945 ; 1946$ to 1970 ; and 1971 to the present. It is clear that older houses are concentrated in WARD-1 in the severe-damage zone. WARD-1 was therefore excluded from subsequent investigation. (Right) Comparison of DL for houses in WARD-2 constructed prior to 1980 and after 1981. DL distribution is very similar for the two periods of construction.

$\mathrm{DL}=0$ to 1 in the slight-damage zone is more than $80 \%$, that of DL $=1$ to 3 in the moderate-damage zone is about $85 \%$, and that of DL more than 3 in the severe-damage zone is about $55 \%$. Furthermore, the proportion of DL higher than 3 increases from 15 to $55 \%$ from the slight-damage zone to the severe-damage zone. The zoning of damage distribution based on DL therefore appears reasonable.

We investigated the damage distribution in Shimoenoki without taking into account the year of construction of the wooden houses. As mentioned above, however, there are houses of 100 to 120 years in age in WARD-1 where the damage was severe, whereas WARD-2 contains many new houses with ages of 15 to 25 years. Therefore, the influ- ence of building age on the damage distribution should be examined for wooden houses. For this purpose, a distribution map of houses classified by construction year was produced using the following categories; before 1900, from 1901 to 1945 , from 1946 to 1970 , and from 1971 to the present. This map is shown in Fig. 6. From this map it is clear that the older houses, those constructed prior to 1945 , are concentrated in WARD-1 where the degree of damage was most severe. There is no such significant concentration of severe damage in a specific area in WARD-2. Although it remains unclarified whether the severe damage in WARD-1 is due to the older ages of the houses, WARD-1 was excluded from the present analysis in Shimoenoki in order to more accurately 
(a)

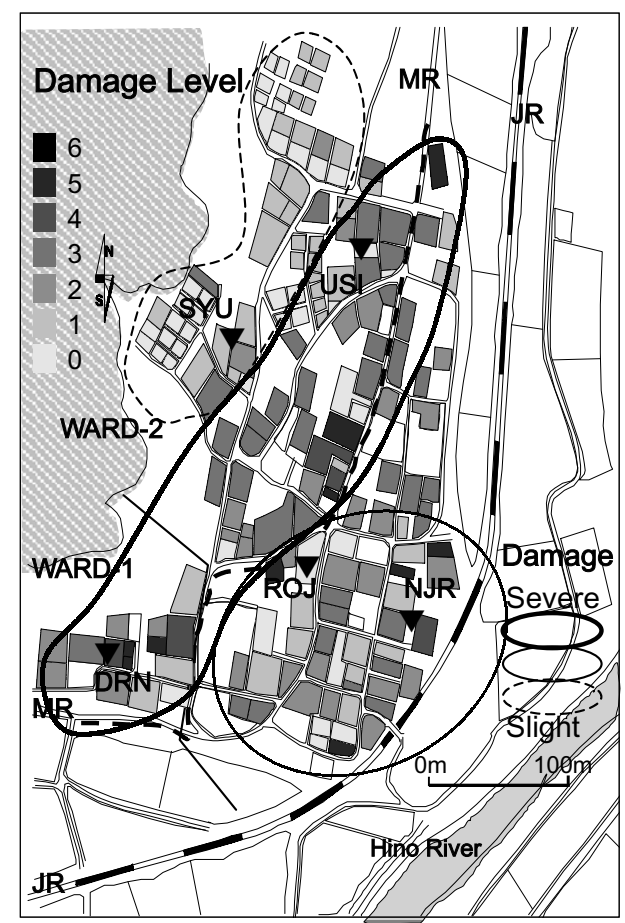

(b)
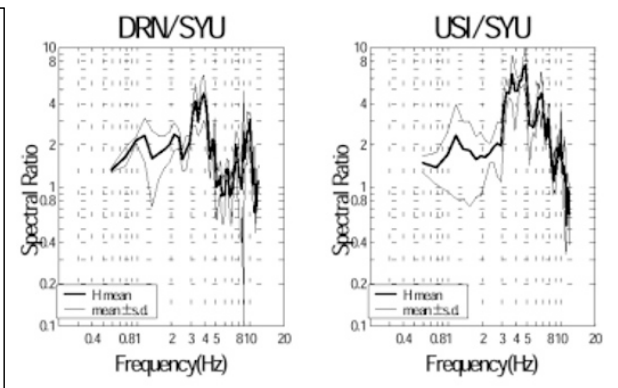

$\mathrm{ROJ} / \mathrm{SY}$

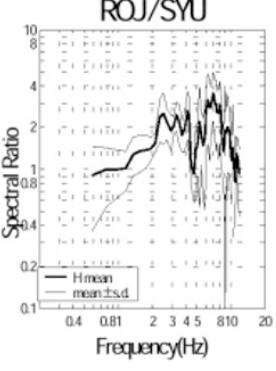

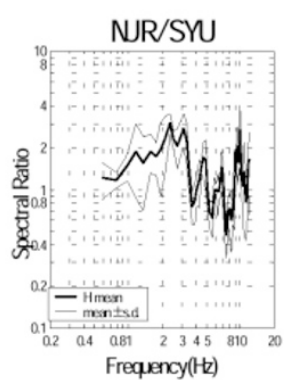

Fig. 7. (a) Comparison of damage distribution of wooden houses and (b) local site-amplification estimated using S waves from aftershocks. Station SYU in the slight-damage zone was used as a reference station. Stations DRN and USI are located in the severe-damage zone, and ROJ and NJR in the moderate-damage zone. There is a good correlation between the amplification factor at frequencies of 2 to $5 \mathrm{~Hz}$ and the damage level.

assess the damage distribution due to local amplification.

The same age dependency in the damage distribution for WARD-2 was also examined. WARD-2 contains relatively new buildings, and the map of buildings classified by construction year reflects this (Fig. 6). Even so, there exist a number of houses built before 1971, prior to the revisions to the Japanese Building Standard Law in 1981. However, the damage levels for houses in this region are similar for houses built prior to and after 1981, indicating that the damage distribution for wooden houses in WARD-2 in Shimoenoki appears to be independent of the year of construction. Therefore, in the following, the relationship between the damage distribution and local site amplification is discussed with respect to WARD-2.

\section{Local Site Amplification Estimated from After- shock Records}

In order to estimate local site amplification in Shimoenoki, aftershocks were observed using velocity-sensors at five sites; SYU, ROJ, NJR, DTR and USI, for the period from October 15 to December 29, 2000 (Matsunami et al., 2001). Figure 7(a) shows a configuration map of the observation sites in Shimoenoki. As shown in this figure, SYU is located near the foot of the mountains in northwestern Shimoenoki and is within the slight-damage zone. ROJ and NJR are located in the moderate-damage zone, and USI and DRN are located in the severe-damage zone. A total of 23 aftershocks were used to estimate local amplification. The epicenter distribution of those events is shown in Fig. 1. The range of magnitude (M) was 1.8 to 3.9 , and the hypocenters were within $12 \mathrm{~km}$ of the surface. Figure 8 shows an example of aftershock records observed simultaneously in Shimoenoki. The relative amplification of each observation site was estimated by taking spectral ratios between each site and a reference site. Here, SYU was used as the reference site because SYU is located on hard soil near the foot of the mountains. No correction was made for geometrical spreading of the wavefront or for attenuation of seismic waves due to scattering and absorption of wave energy because the hypocentral distance was very large compared to the distance between observation sites. In the calculation of the spectral ratio, a horizontal component spectrum (H-component spectrum), composed by vectorially summing the spectra of the NS and EW components of ground motion, was used. The analyzed interval is $5 \mathrm{~s}$ from the onset of the $\mathrm{S}$ waves. In calculating the Fourier spectrum, a Hanning-type window with a taper of 5\% was employed on both ends of the analyzed interval. In addition, the spectrum was smoothed over a bandwidth of $0.4 \mathrm{~Hz}$. Figure 7(b) shows the amplification characteristics for each observation site, and Fig. 7(a) shows the damage distribution of wooden houses in Shimoenoki. The amplification characteristics at USI within the severe-damage zone exhibit a clear peak with an amplification factor of 6 to 7 at frequencies of 3 to $5 \mathrm{~Hz}$, and DRN within the same zone shows a clear peak with an amplification factor of 5 to 6 at frequencies of 3 to $4 \mathrm{~Hz}$. ROJ within the moderate-damage zone has a peak with an amplification factor of 2 to 2.5 at frequencies of 2.5 to $4.5 \mathrm{~Hz}$, and that of NJR within the same zone has a peak with an amplification factor of about 3 at frequencies of 2 to $3.5 \mathrm{~Hz}$. The reference site SYU is within 


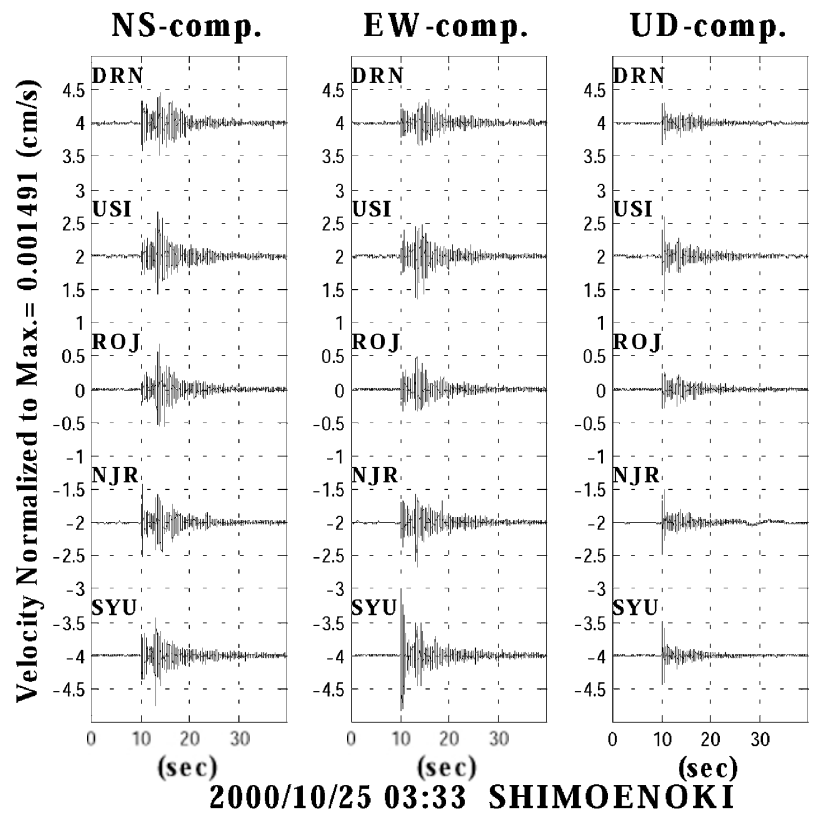

Fig. 8. An example of aftershock records observed simultaneously at stations in Shimoenoki. The magnitude of this event is 2.1 , with a focal depth of $8.2 \mathrm{~km}$.

the slight-damage zone. From this data, it appears that the local amplification characteristics in Shimoenoki are characterized by significant peaks at frequencies of 2 to $5 \mathrm{~Hz}$, and there is a good correlation between the amplification factor at frequencies of 2 to $5 \mathrm{~Hz}$ and the damage level.

Midorikawa and Fujimoto (2000) carried out microtremor measurements in various cities and towns damaged by the 2000 Western Tottori Earthquake and estimated the predominant period of soil sediments from the $\mathrm{H} / \mathrm{V}$ ratio method presented by Nakamura (1989). According to their observations, the predominant period is $0.4 \mathrm{~s}$ at Shimoenoki. It has also been reported by Hayashi et al. (2001) that the fundamental peak of the $\mathrm{H} / \mathrm{V}$ ratio in Shimoenoki can be seen at 3 to $5 \mathrm{~Hz}$. These results obtained from the H/V ratio using microtremors agree well with the present results derived using aftershock records.

\section{Vibrational Characteristics of Wooden Houses Evaluated from Microtremors}

In order to examine vibration characteristics of wooden houses in Shimoenoki, the transfer functions of wooden houses was determined from microtremors measured simultaneously on soil outside the house and on the second floor using a three-component velocity-type seismometer (Matsunami et al., 2001; Kobayashi et al., 2001). Of the eight houses studied, two were damaged, five had been repaired and the remaining one was under reconstruction. Figure 9(a) shows the location of these houses. The first natural frequency of the houses was determined from the frequency of the first fundamental peak of the transfer function. The two horizontal components of the seismometer were set in the directions of the span and girder of the houses, allowing the natural frequency to be determined for both directions. The microtremor measurements were performed over $3 \mathrm{~min}$, and repeated 5 times. The Fourier spectra were calculated using time windows of about $40 \mathrm{~s}$, and with smoothing over a bandwidth of $0.4 \mathrm{~Hz}$.

In addition to the first natural frequency, the damping factor ( $h=1 / 2 Q, Q$ : Q-factor) of the houses was evaluated from the width of the first fundamental peak of the transfer function. When the main spectral peak has a maximum amplitude centered at a frequency $f_{0}$ and a width $\delta f, 1 / Q=$ $\delta f / f_{0}$, where $\delta f$ is the width of the spectral band at $1 / \sqrt{2}$ of the maximum peak amplitude.

The natural frequencies and the damping factors for all the measured houses are summarized in Table 2. Figure 9(b) gives examples of the transfer functions thus evaluated. The examples in this figure are for Houses NM and IR, which suffered severe damage. The first natural frequency of House $\mathrm{NM}$ is about $3.8 \mathrm{~Hz}$ in both the span direction and the girder direction, whereas that of House IR is 2.5 to $2.7 \mathrm{~Hz}$ in both directions. Thus, the first natural frequency of House IR is low compared to House NM. Although both House IR and House NM are in the severe-damage zone, the DL of House IR $(D L=5)$ is higher than that of House NM $(D L=3)$. In addition, House IR (120 years) is much older than House NM (20 years). The difference in the natural frequency for these two similar houses is therefore thought to be due to differences in the nature of the unrepaired damage and difference in age.

For the five repaired houses, the first natural frequency ranges from 3.3 to $4.7 \mathrm{~Hz}$ and 3.0 to $5.3 \mathrm{~Hz}$ in the span and girder directions, respectively. As the range of natural frequencies is similar in both directions, the first natural frequency of the repaired houses is approximated as 3 to $5 \mathrm{~Hz}$. The result of 2.5 to $3.8 \mathrm{~Hz}$ for the damaged houses, as shown above, is slightly lower than the result for the repaired dwellings. This appears to be because the houses sustained substantial deformation and damage during the main shock, effectively lowering the natural frequency.

One house under reconstruction was also analyzed. The first natural frequency was $4.0 \mathrm{~Hz}$ and $4.3 \mathrm{~Hz}$ in the span and girder directions, respectively, which are within the range of natural frequency for the repaired houses ( 3 to $5 \mathrm{~Hz}$ ).

As mentioned above, the results for the damaged houses appear to be affected by the non-linear response of houses to ground motion. Therefore, it is appropriate to assume that the natural frequency of wooden houses in Shimoenoki before the earthquake would have been similar to the frequency obtained for the repaired houses in this study. The first natural frequency of wooden houses in Shimoenoki is approximately 3 to $5 \mathrm{~Hz}$, which coincides with the peak frequency of site-amplification ( 2 to $5 \mathrm{~Hz}$ ) in Shimoenoki. This range of natural frequencies is also similar to that in Yonago City (Report of Damage by the 1943 Tottori Earthquake, 1983) and Kobe City (Suzuki and Nakaji, 1995).

Although the damping factor for wooden houses varies from building to building as seen in Table 2, there are no significant differences between the severely damaged houses, repaired houses and house under reconstruction. However, the damping factor in the girder direction for House IR is very large compared with the other buildings. This also appears to be due to that the house sustained the large deformation and damage due to shaking from the main shock, resulting in greater absorption of vibration energy. Therefore, 
(a)

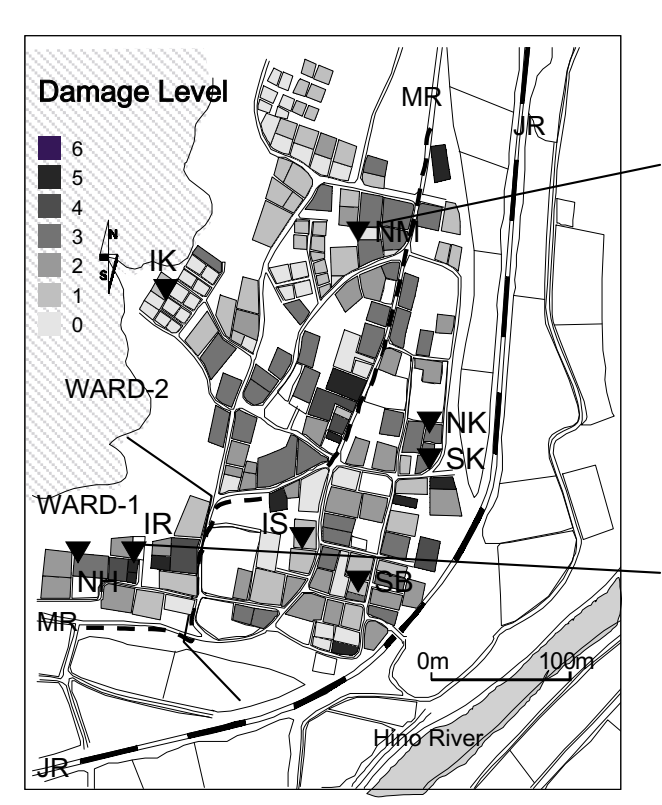

(b)
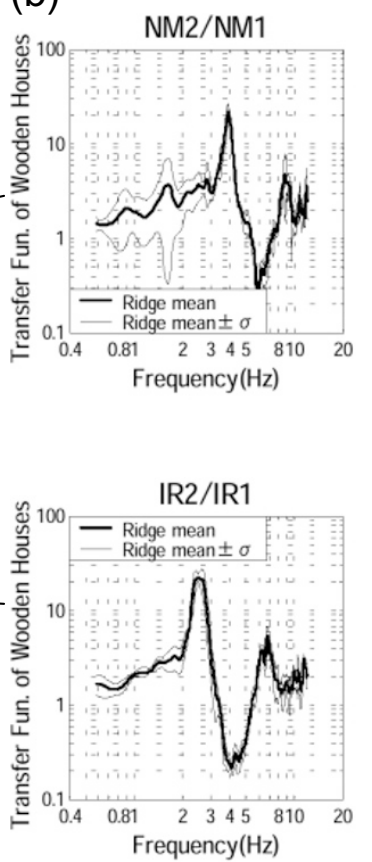
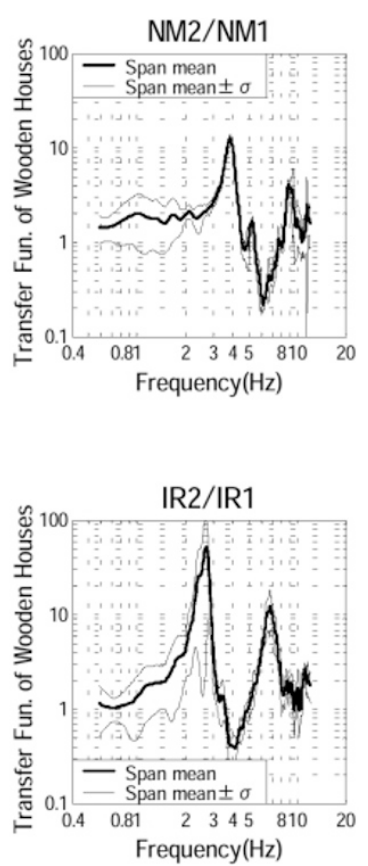

Fig. 9. (a) Location of wooden houses analyzed in the evaluation of vibrational characteristics in response to microtremors and (b) examples of obtained transfer functions. Transfer functions were derived by the taking spectral ratios of the second floor of the house (NM2 and IR2) to a reference soil site outside the house (NM1 and IR1). The first natural frequency and damping factor in the girder and span directions of the houses (NM and IR) were determined from the frequency and the width of the first fundamental peak of transfer functions.

Table 2. Results of damage survey and evaluation of vibrational characteristics for sampled houses.

\begin{tabular}{|c|c|c|c|c|c|c|c|}
\hline \multirow{2}{*}{$\begin{array}{c}\text { Name of } \\
\text { house }\end{array}$} & \multirow[b]{2}{*}{ Construction year } & \multicolumn{2}{|c|}{ Damage level* } & \multicolumn{2}{|c|}{$\begin{array}{l}\text { First natural } \\
\text { frequency }(\mathrm{Hz})\end{array}$} & \multicolumn{2}{|c|}{ Damping (\%) } \\
\hline & & Hino Town Office & This study & Girder & Span & Girder & Span \\
\hline IS & 1984 & Partial collapse & 1 & 3.7 & 4.7 & 3.9 & 3.6 \\
\hline NK & 1982 & Partial collapse & 3 & 5.3 & 4.2 & 3.2 & 4.0 \\
\hline IK & 1984 & Partial collapse & 1 & 3.9 & 3.3 & 3.1 & 3.6 \\
\hline $\mathrm{NH}$ & 1895 & Partial collapse & 3 & 3.0 & 3.3 & 4.7 & 3.4 \\
\hline SK & 1983 & Partial collapse & 3 & 4.4 & 4.2 & 2.2 & 3.9 \\
\hline SB & Under reconstruction & - & - & 4.3 & 4.0 & 3.3 & 3.0 \\
\hline IR & 1880 & Total collapse & 5 & 2.5 & 2.7 & 8.1 & 3.1 \\
\hline NM & 1980 & Partial collapse & 3 & 3.8 & 3.8 & 3.1 & 4.8 \\
\hline
\end{tabular}

* The judgment of damage level by Hino Town Office was done based on the detail investigation of damage. Although our judgment is mainly based on the appearance of damaged houses, there is a good correlation between both judgments.

the values for House IR are excluded in the estimation of the damping factors in Shimoenoki. The damping factor in this final set of buildings varies by 2 to $5 \%$ in each group, which is similar to that recorded for Kobe City (Suzuki and Nakaji, 1995).

\section{Discussion}

The damage survey in Shimoenoki revealed that despite the relatively small area of the town, only $300 \times 400 \mathrm{~m}^{2}$, three distinct zones of damage can be identified from the foot of the mountains to the Hino River according to the distribution of the damage level for wooden houses. The cause of damage was examined by comparing the damage distri- bution, local site amplification and vibration characteristics of wooden houses on the assumption of the linear behavior of soils and wooden houses, using weak motion from aftershocks and microtremors. By taking spectral ratios using the aftershock records, site amplification in Shimoenoki was found to be characterized by a significant peak at frequencies of 2 to $5 \mathrm{~Hz}$. This coincides with the distribution for the damage level of wooden house. Furthermore, from the transfer function of wooden houses, evaluated using microtremors, the first natural frequency of these building is approximately 3 to $5 \mathrm{~Hz}$. Therefore, the damage distribution for wooden houses in Shimoenoki appears to be primarily attributable to the difference in site-amplification factors at frequencies of 
2 to $5 \mathrm{~Hz}$, which coincides with the first natural frequencies of wooden houses in this area.

As mentioned in Section 2, Unoike, about $2 \mathrm{~km}$ west of Shimoenoki, experienced strong ground motions during the main shock. The borehole station UN1 observed a peak acceleration of about $418 \mathrm{~cm} / \mathrm{s}^{2}$ and a peak velocity of about $42 \mathrm{~cm} / \mathrm{s}$ in the N-S component. Hayashi et al. (2001) inferred from the distribution of fallen tombstones that the peak velocity was 80 to $100 \mathrm{~cm} / \mathrm{s}$ around Shimoenoki. Furthermore, the small $\mathrm{N}$ values at shallow depths at boring site N4 in central Shimoenoki indicate that the soil in central Shimoenoki is soft. Therefore, the non-linear behavior of soils and wooden houses in central Shimoenoki should be considered.

In general, non-linearity of soils results in a shift of the predominant frequency of soil to lower frequencies and suppression of ground motion amplification. Similarly, the nonlinearity of buildings leads to the absorption of vibration energy and a lowering of the natural frequency of the buildings. In Section 5, from comparisons of the natural frequencies and damping factors between the damaged and repaired houses, such a shift of the natural frequency and absorption of vibration energy (i.e., increase in damping factor) for wooden houses was identified in central Shimoenoki (Table 2). This is considered clear evidence of the non-linearity of severely damaged wooden houses. No clear evidence reflecting the non-linearity of soils was found in central Shimoenoki.

In order to explain more precisely the damage to wooden houses in central Shimoenoki, it is necessary to take into account the non-linearity of soils and wooden houses during the main shock in estimating the site amplification and the vibration characteristics of wooden houses. However, to examine theoretically the non-linearity of soil sediments, a model of the subsurface structure is required in addition to main shock records. Similarly, in order to examine the nonlinearity of wooden houses, a model of input motion and reasonable hysteresis for wooden-framed structures in central Shimoenoki is necessary. Although only limited data is currently available for examining this non-linearity, the present authors are currently working on the problem and will report the results in the future.

\section{Conclusions}

The degree of damage to wooden houses in the vicinity of the source area of the 2000 Western Tottori Earthquake was very low compared to that incurred in the 1995 Hyogo-ken Nanbu Earthquake. The damage to Shimoenoki, Kurosaka, Shimokurosaka and Yasuhara in Hino Town, however, was severe. Shimoenoki, which is about $10 \mathrm{~km}$ southeast of the main shock epicenter, suffered remarkable damage, particularly to residential wooden houses. Shimoenoki, although representing only a small area of $300 \times 400 \mathrm{~m}^{2}$, exhibited spatial variation in the extent of damage to wooden houses from the foot of the mountains to the Hino River, which is the largest river in Hino Town. In this study, the cause of such a spatial variation of damage in Shimoenoki was examined based on the damage distribution, obtained through a survey of all wooden houses conducted after the earthquake, the local site-amplification characteristics estimated using aftershock records, and the vibrational characteristics of wooden houses evaluated using microtremors. These results were analyzed assuming linear behavior of soils and wooden houses in response to weak motions from aftershocks and microtremors.

From the damage survey, Shimoenoki was found to contain three discrete zones of housing damage; slight-, severeand moderate-damage zones, extending from the foot of the mountains to the Hino River in this order. From spectral ratios obtained using aftershock records, site amplification in Shimoenoki was found to be characterized by significant peak at frequencies of 2 to $5 \mathrm{~Hz}$. Then, from the transfer function of wooden houses evaluated using microtremors, the first natural frequency of the houses was found to be approximately 3 to $5 \mathrm{~Hz}$ with a damping factor of 2 to $5 \%$. Based on these three findings, the spatial variation of damage appears to be attributable to the variation in siteamplification factors at frequencies of 2 to $5 \mathrm{~Hz}$, which is close to the first natural frequency of wooden houses.

Furthermore, it was found that the natural frequency of damaged houses was lower than that of repaired houses, whereas the damping factor was higher. This result suggests that the soils and wooden houses in central Shimoenoki exhibited non-linear behavior during the main shock, and this non-linearity remains an important subject of future research.

Acknowledgments. The authors would like to thank everyone who assisted with the temporary observations at the stations in Shimoenoki, Hino Town, the people of Shimoenoki who took part in the survey, and the Hino Town Office for providing valuable material regarding earthquake damage. Gratitude is extended to Jim Mori for helpful comments concerning revision of the manuscript, Kunihiro Shigetomi and Wataru Morii for assistance in setting up and maintaining the instruments at the temporary stations, and Kensuke Onoue, Misako Hirata and Yasuhisa Nagawa for help with surveying the damaged area. Data from Kik-Net TTRH02 of the National Research Institute for Earth Science and Disaster Prevention, Japan, was used in the estimation of strong motions during the main shock.

\section{References}

Hayashi, Y., A. Kitahara, T. Hirayama, and Y. Suzuki, Evaluation of peak ground velocities in western Tottori earthquake of 2000, Journal of Structural and Constructions Engineering (Transactions of Architectural Institute of Japan), 2001 (submitted, in Japanese).

Kitahara, A., Y. Suzuki, and M. Goto, Damage to wooden houses in Hino Town, Reports of the damage investigation for wooden buildings by the 2000 Western Tottori Earthquake, Reconstruction of Wooden Structural Mechanics and Revival of Timber Culture, Kinki Branch, Architectural Institute of Japan (AIJ), Special Research Committee of AIJ for Reconstruction of Wooden Structural Mechanics and Revival of Timber Culture, pp. 210-218, 2001 (in Japanese).

Kobayashi, M., T. Fujiwara, K. Fukumoto, M. Ito, T. Morii, K. Nakano, and Y. Okamoto, Dynamic characteristics and damage ratio of wooden houses in Shimoenoki, Hino Town: Part I in Report of the 2000 Western Tottori Earthquake, Proceedings of Architectural Institute of Japan Tyugoku Chapter Architectural Research Meetings, 367-370, 2001 (in Japanese).

Matsunami, K., T. Fujiwara, T. Morii, and Y. Okamoto, Site amplification of the Shimoenoki area obtained from aftershocks and microtremors: Part II in Report of the 2000 Western Tottori Earthquake, Proceedings of Architectural Institute of Japan Tyugoku Chapter Architectural Research Meetings, 371-374, 2001 (in Japanese).

Midorikawa, S. and K. Fujimoto, Prompt report of damage investigation for the 2000 Western Tottori Earthquake, Earthquake Engineering Research Group, Tokyo Institute of Technology, Earthquake Engineering Research 
Report, No. 76, 51-56, 2000.

Nakamura, Y., A method for dynamic characteristics estimations of subsurface using microtremors on the ground surface, QR RTRI, 30, 25-33, 1989.

Report of Damage by the 1943 Tottori Earthquake, Research Group for Regional Disaster Prevention, Yonago National College of Technology, 1983 (in Japanese).

Suzuki, Y. and H. Nakaji, Vibration characteristics of wooden houses evaluated by microtremor measurements, Damage to Wooden Buildings by the
1995 Hyogo-ken Nanbu Earthquake, Kinki Branch, Architectural Institute of Japan, 169-174, 1995 (in Japanese).

Tottori Prefecture Office, Nature in Tottori Prefecture, Topography and geology, 1993 (in Japanese).

Yoshida, N., Subsurface investigation and soil dynamics: Part II, in Earthquake Motion and Ground Conditions, Architectural Institute of Japan, pp. 232-233, 1993.

K. Matsunami (e-mail: matunami@egmdpri01.dpri.kyoto-u.ac.jp), T. Morii, Y. Okamoto, and T. Fujiwara 